\title{
Impact of stabilized leachate residues from the uncontrolled landfill of Mohammedia city on the "'Oued El Maleh" river and on the soil
}

\author{
M. Laaouan' ${ }^{1}$, S. Souabi ${ }^{1}$, M. A. Aboulhassan ${ }^{2}$, M. Tahiri ${ }^{3}$ \\ ${ }^{I}$ Faculty of Science and Technology, University of Hassan II-Mohammedia, Morocco \\ ${ }^{2}$ National School of Applied Sciences of Agadir, BP 1136, AGADIR, Morocco \\ ${ }^{3}$ Faculy of Science Aîn Chock, Km 8, Road of El Jadida B.P 5366 Maarif, Casablanca 20100, Morocco
}

\section{Keywords \\ $\checkmark$ Pollution, \\ $\checkmark$ Landfill, \\ $\checkmark$ Leachate, \\ $\checkmark$ metals, \\ $\checkmark B O D$ \\ $\checkmark C O D$}

Received 16 Apr 2017, Revised 22 Aug 2017, Accepted 29 Aug 2017

mlaaouan@gmail.com

Phone: (+212) 660954943

\begin{abstract}
The evaluation of pollution generated by residues of the uncontrolled landfill of Mesbahiat of Mohammedia city at the level of the river "Oued El Maleh"(OMR), nearby soil and puddles of leachate from their percolation in the soil, show that the river and the surrounding sheet are still threatened by non-biodegradable inorganic pollution despite the closure of this landfill more than six years ago. These leachate puddles have very high electrical conductivities ranging from 34600 to $40900 \mu \mathrm{S} / \mathrm{cm}$ and that obtained at the river is about $4610 \mu \mathrm{S} / \mathrm{cm}$. These high values are due to the presence of high concentrations of mineral salts, $\mathrm{K}^{+}, \mathrm{Na}^{+}, \mathrm{Mg}^{2+}, \mathrm{Ca}^{2+}$ responsible for salinity and hardness, and various metals with varied forms. The concentrations of these salts in the stabilized leachate, as well as the metals $\mathrm{As}, \mathrm{Cd}, \mathrm{Cr}, \mathrm{Cu}, \mathrm{Ni}, \mathrm{Pb}, \mathrm{Zn}, \mathrm{V}, \mathrm{Cr}, \mathrm{Mn}$ and $\mathrm{Ni}$ are higher than those of the river water. Otherwise, Aluminum concentrations are very high in the river water samples compared to the leachate samples. For the same landfill, the results obtained for the metals, compared with those obtained by some previous studies shows that the metallic pollution generated by these metals decreased after six years of the landfill closure. The high COD content (1200 to $7700 \mathrm{mg} \mathrm{O}_{2} / \mathrm{l}$ ) and the absence of BOD in the leachate samples reflect the introduction of non-biodegradable into the puddles of leachate, as well as the removal of biodegradable organic pollutants as the original leachate percolates into the soil before reaching the river edges. The metal analysis of soil samples near and far from puddles indicates that the soil seems to be less contaminated by leachate residues.
\end{abstract}

\section{Introduction:}

The Human development and industrial activities inevitably contribute to the increase of the production of waste which has adverse impacts on human and animal health and on water and soil resources. The treatment of these wastes and their disposal becomes imperative. So, any problem lies in finding a suitable solution, ecologically compatible and in harmony with environmental guidelines and socio-economic interests. At the present time, the management of household waste at the source (sorting and upgrading) is a major concern for all communities.

Unfortunately, the approach taken with regard to the evacuation and treatment of household refuse (O.M) is far from solving the problem given the colossal quantities produced in Morocco and the type of garbage collected. Considering the moisture content and the richness of fermentable organic matter in household waste from developing countries such as Morocco, composting is a promising sector.

The city of Mohammedia with 404648 inhabitants according to the latest census 2014 is currently evacuating its solid waste in the new public dump, located at the rural commune of Benyakhlef place, said Chaâba El Hamra. Before 2011, these wastes are open-air evacuated in the former uncontrolled landfill located in Mesbahiat in the commune of Chellalate. Since its commissioning in 1987, it had constituted a real environmental threat. All household, industrial, banal and specific wastes, hospital and medical wastes (specific and at risk) as well as those of slaughterhouses had always been deposited there. This situation had led to serious public health problems posing a real threat to the ecosystem. 
The dumping of raw wastes, from various urban, industrial and hospital origins, results in an intense production of highly concentrated liquids of mineral and organic matter, called leachate. The latter is the result of the percolation of rainwater through the deposits, as well as waters contained in the wastes and that of their degradation [1]. Several studies have been carried out on the characterization and treatment of these effluents [2-6] in different landfills worldwide.

The objective of this work is to study the impact and degradation of the soil and water quality of the Oued El Maleh River (OMR), near the Mesbahiat landfill closed more than six (06) years ago.

\section{Materiel and Methods}

\subsection{Study area and sampling points}

The Mesbahiat landfill is located in the south-west of Mohammedia near an important urban area (about $5 \mathrm{~km}$ from the city) and the OMR. It covers an area of six (06) hectares alongside the A3 and N1 roads. It's an old quarry of limestone characterized by schists and representing fissures [7]. Figure 1 shows the geographical location of the study area.

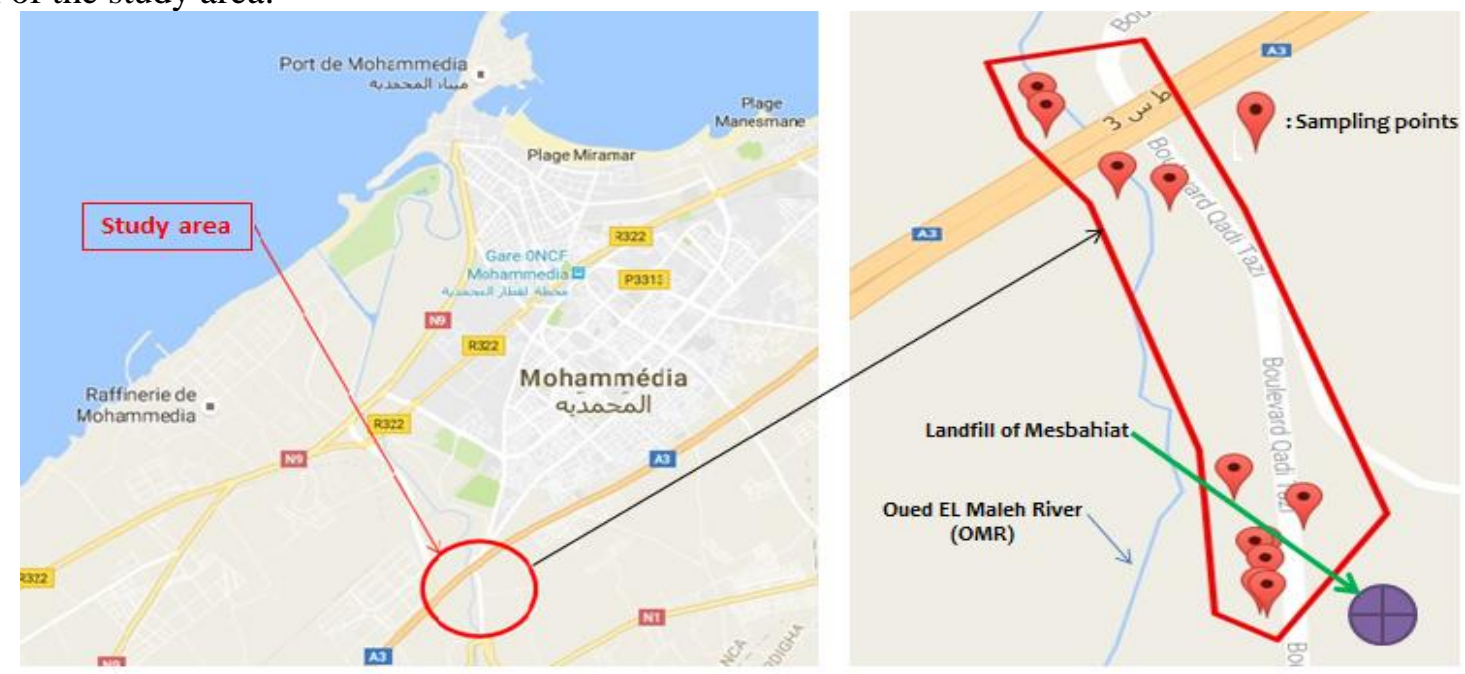

Figure 1: Geographical location of the study area

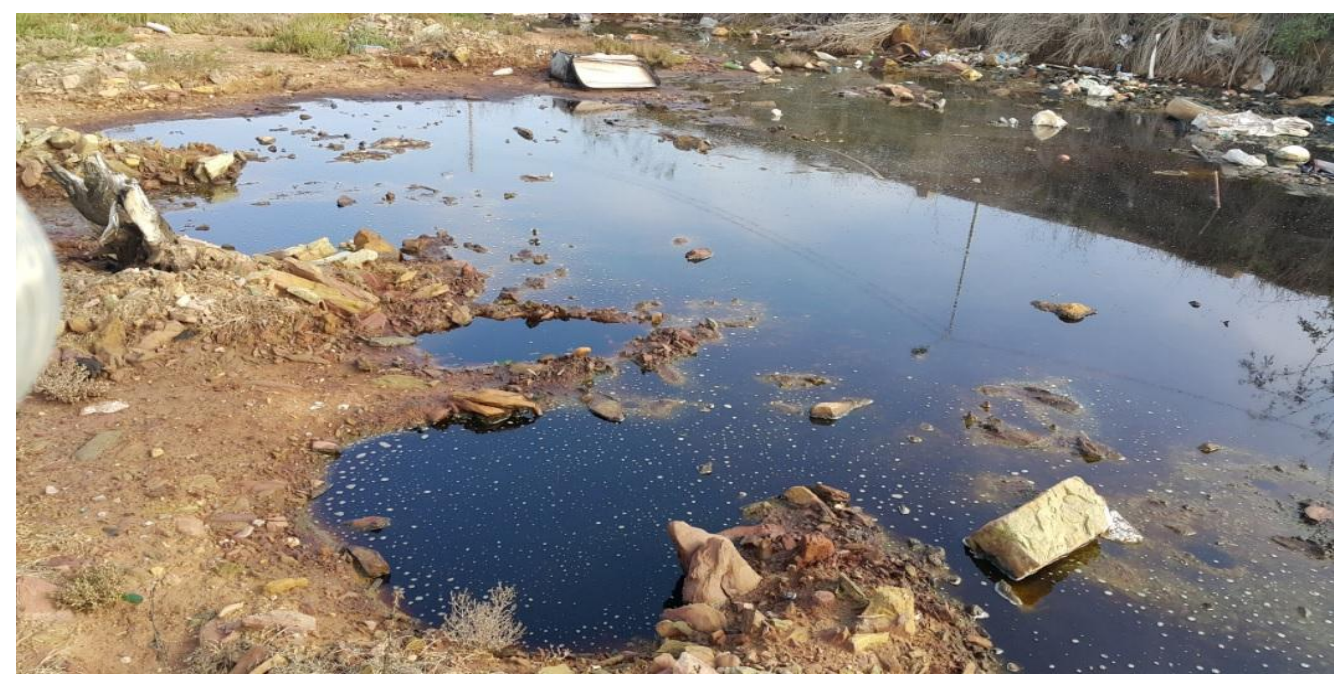

Figure 2: Leachate puddles subject of the study

The liquid samples are taken from the leachate puddles and from OMR prior and after the discharge point of a wastewater stream emanating from a small agglomeration near the landfill (fig3).

- L1 : Sample of stabilized leachate (about $30 \mathrm{~cm}$ deep)

- $\quad$ L2 : Sample of stabilized leachate (about $10 \mathrm{~cm}$ deep)

- E3 : Sample of water from the OMR prior to wastewater stream discharge

- E4 : Water sample from the OMR after the wastewater stream discharge

- L5 : Leachate sample wich flush at roadside N1 
Figure 3 shows the geographical location of the sampling points:

Coordinates of sampling points for different leachate, water and wastewater samples:

$\begin{array}{cccc} & \text { X (in m) } & \text { Y (in m) } & \text { Z (in m) } \\ \text { L1 } & 314497.51 & 342174.02 & 9.66 \\ \text { L2 } & 314496.93 & 342195.57 & 9.34 \\ \text { E3 } & 314376.08 & 342586.11 & 11.37 \\ \text { E4 } & 314519.77 & 342245.14 & 11.7 \\ \text { L5 } & 314418.83 & 342519.9 & 10.86\end{array}$

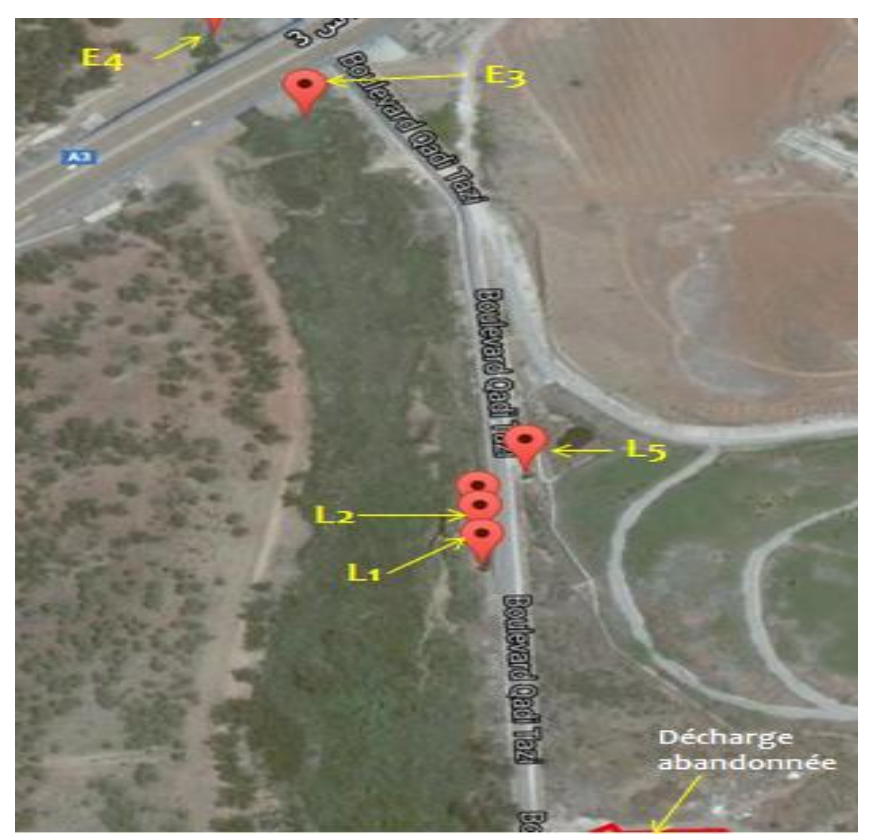

Figure 3: Localization of the sampling points of leachates, water and wastewater

Figure4 shows the geographical location of the sampling points of soil samples:

- $\quad$ S1 and S2 : Wet soil samples (0.5 to 1 meter away from stagnant leachate)

- S3 : Dry soil sample (about 5 meters away from the leachate)

- $\quad$ S4 : Soil sample at the side of OMR (far from about 315 meters from the leachate)

- S5 : Soil sample at the side of OMR (about 412 meters from the leachate)

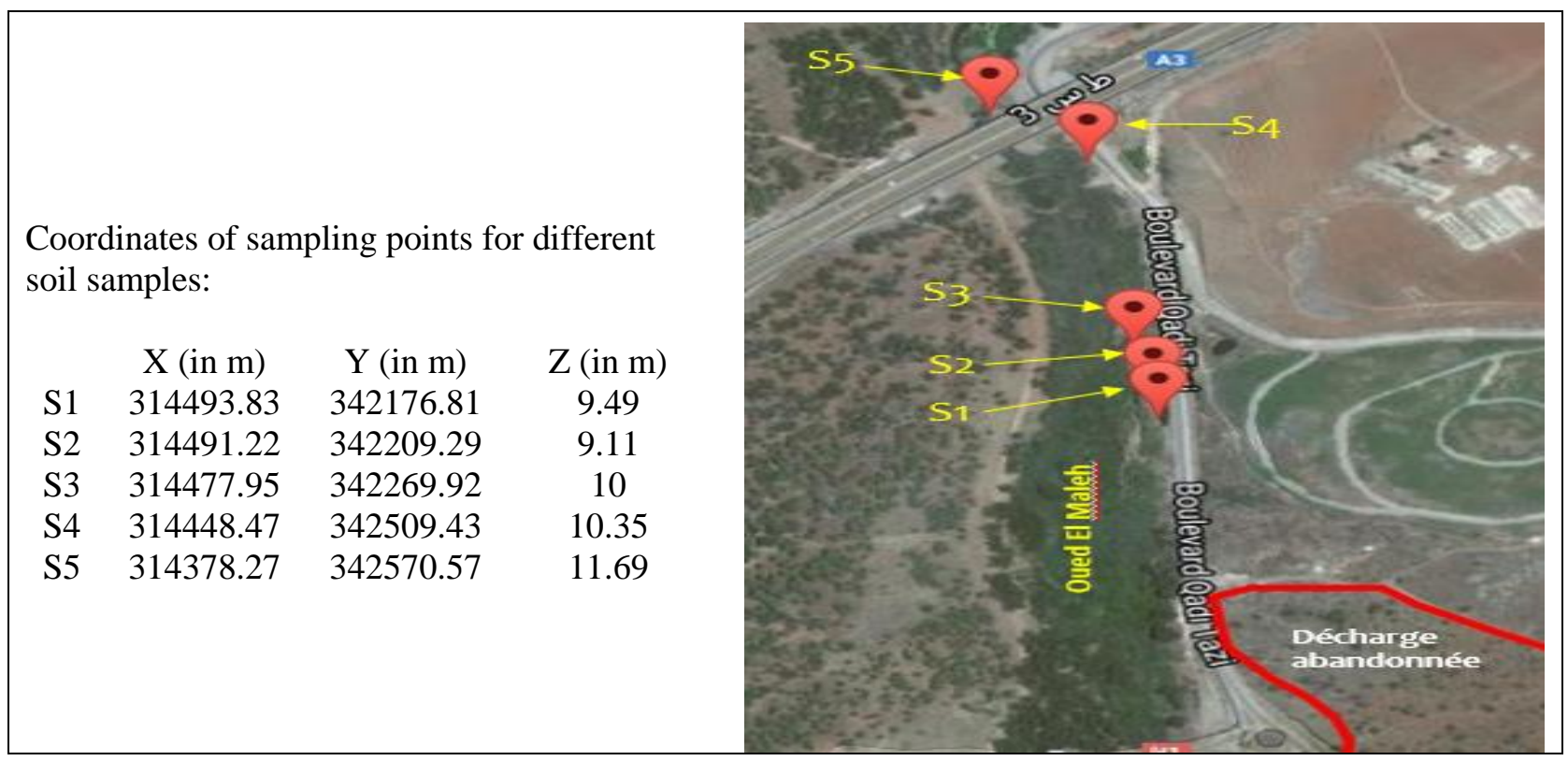

Figure 4: Geographical location of the sampling points of soil samples

\subsection{Water and wastewater samples}

The samples for metals analysis were collected in $250 \mathrm{ml}$ flasks previously acid-washed and rinsed. Samples were conserved in acidic medium $(\mathrm{pH}<2)$ using nitric acid solution $\left(\mathrm{HNO}_{3}\right)$. For analysis, $0.5 \mathrm{ml}$ of concentrated nitric acid is added to each $10 \mathrm{ml}$ of each sample taken in a $50 \mathrm{ml}$ flask. It's then mineralized in a Digest Block at $95{ }^{\circ} \mathrm{C}$ for 2 hours. Instrumental analysis was performed using the Inductively Coupled Plasma Mass Spectrometry (ICP-MS) technique, according to NM ISO 17294-2 (2014) standard. The pH and the conductivity are determined using a "WTW" Multi 3430 instrument. 
COD is determined using the ready-to-use closed tube method. The tube contains all the necessary reagents and it is enough to introduce a precise volume of sample, and to follow the protocol described by the company (HACH LANGER). It is based on the same principle as the standardized tests (ISO 15705); Oxidation of the sample by potassium dichromate in the presence of sulfuric acid, silver sulphate (catalyst) and mercury sulphate (chloride ion complexing agent). The only modifications concern the quantities of samples and the reagents used, as well as the method of measurement (photometric measurement rather than titration). Thus, tank tests require less than $10 \%$ of the amount of reagent used for a determination using a standardized method.

The Biochemical Oxygen Demand $\left(\mathrm{BOD}_{5}\right)$ is defined as the amount of oxygen consumed under the test conditions, that is, after incubation for 5 days at $20^{\circ} \mathrm{C}$ and in the dark by some substances present in water, mainly to ensure their biological degradation. It was determined by applying the dilution method, measuring oxygen consumed within five days by a sample diluted with oxygen saturated water, and then placed in a thermostated enclosure at $20^{\circ} \mathrm{C}$.

\subsection{Soil samples}

Soil samples for metals analysis were collected in plastic bottles. $15 \mathrm{ml}$ of concentrated nitric acid are added to $0.5 \mathrm{~g}$ of each closed soil sample in a flask overnight. Then, samples are placed in a Digest block at $95{ }^{\circ} \mathrm{C}$ for 2 hours. Metal analysis is performed according to NM ISO 17294-2 (2014) standard.

\section{Results and Discussions:}

\subsection{Stabilized leachate and OMR waters}

Analysis results of samples of leachate and OMR waters taken near and far from stabilized leachate puddles are illustrated in Figure5(a), Figure5(b), Figure5(c) and Figure5(d) ). Given the large number of parameters analyzed, the results are broken down according to the concentrations of similar quantities.

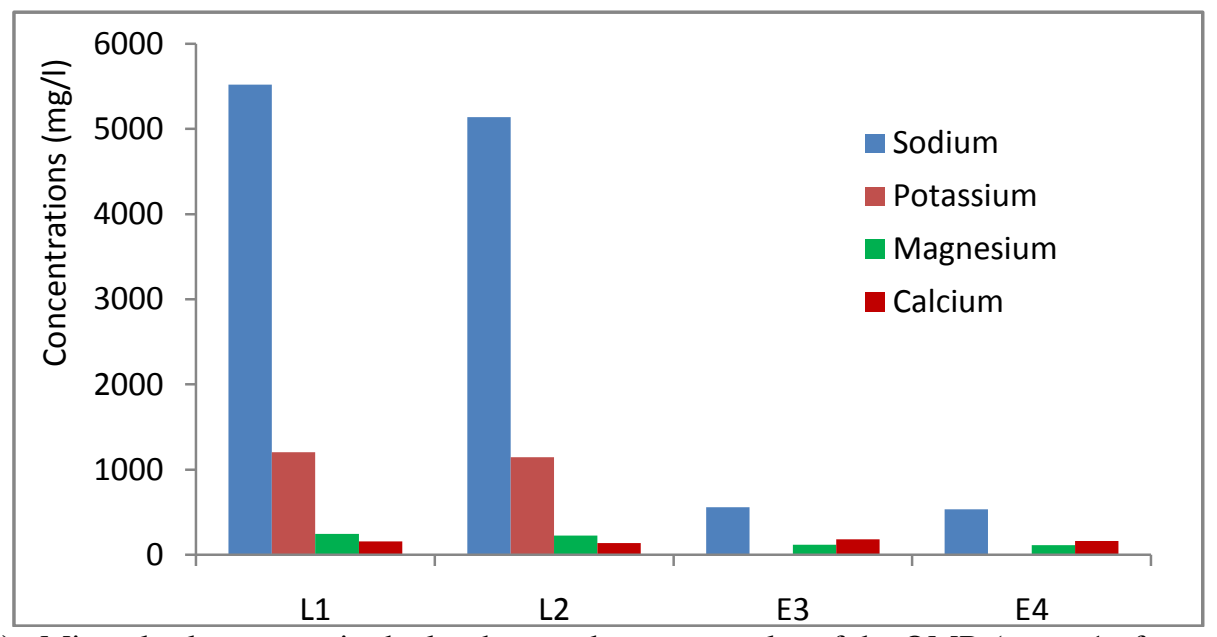

Figure 5(a) : Mineral salt contents in the leachate and water samples of the OMR (range 1 of concentrations)

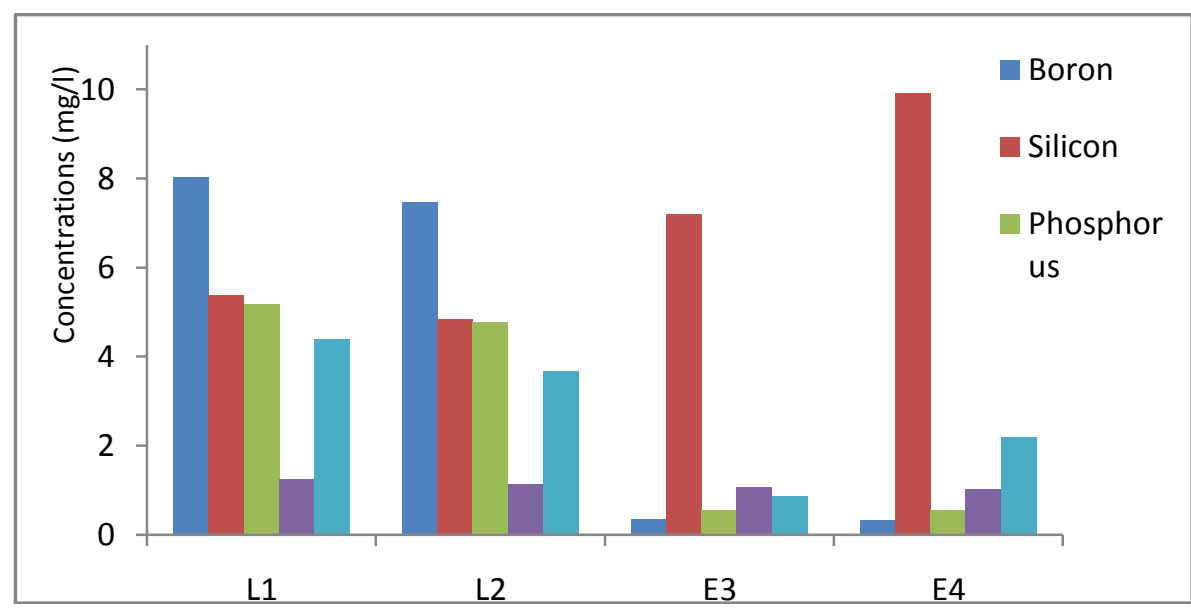

Figure 5(b) : Metal concentrations in the leachate and water samples of the OMR (range 2 of concentrations) 


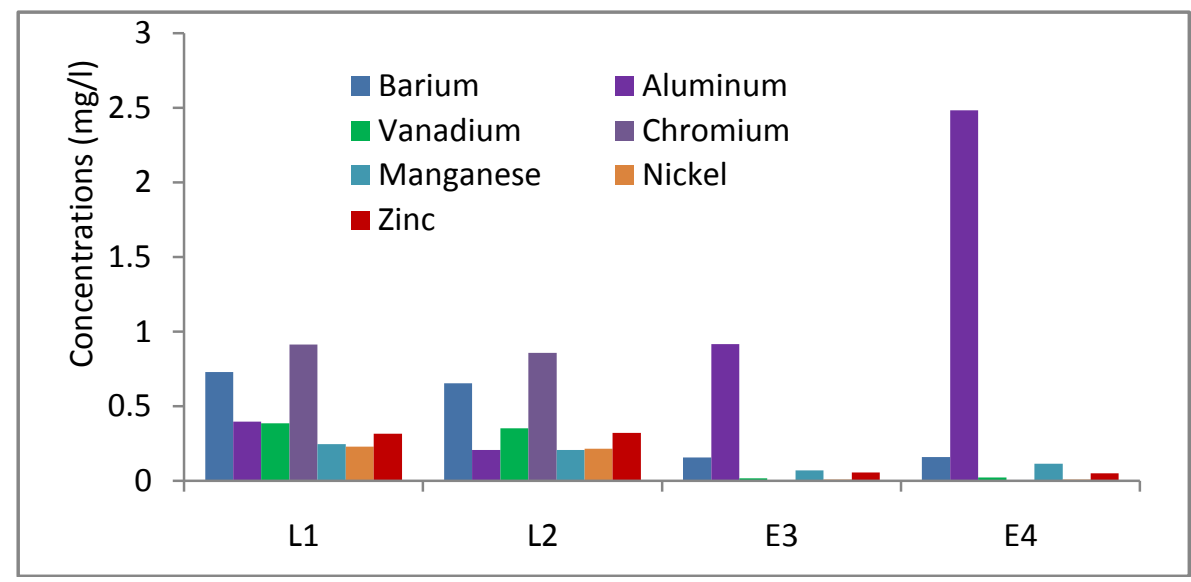

Figure 5(c) : Metal concentrations in the leachate and water samples of OMR (range 3 of concentrations)

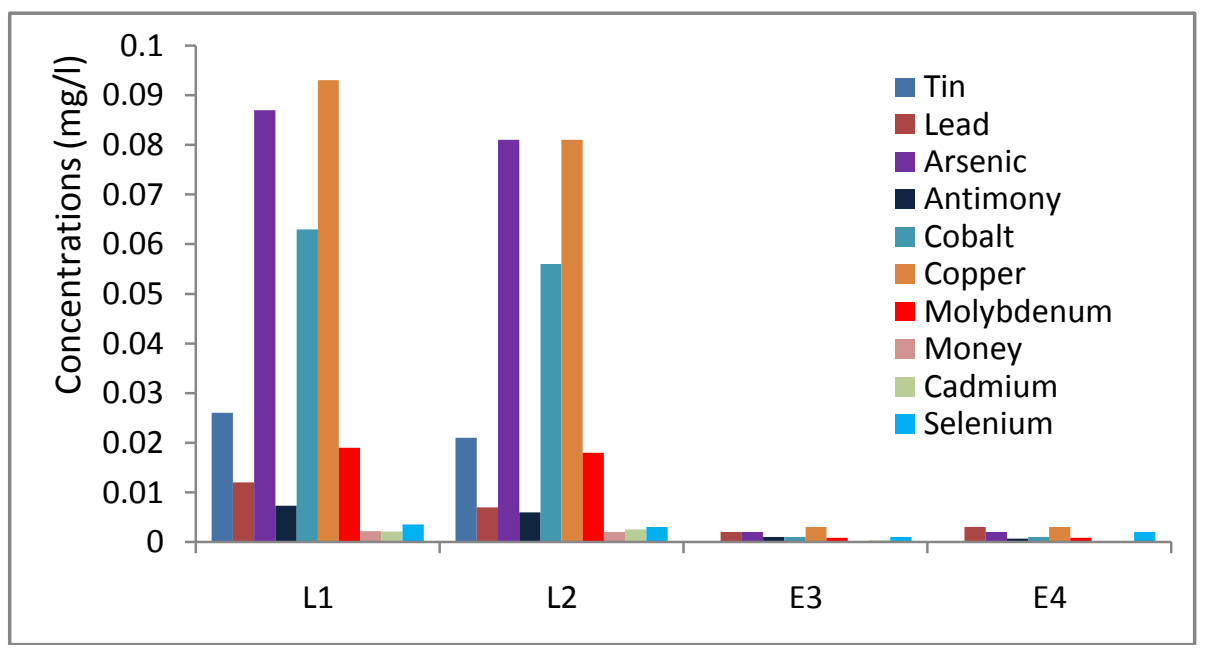

Figure 5(d) : metal concentrations in the leachate and water samples of the OMR (range 4 of concentrations)

The analysis of these results shows high levels of mineral salts and metallic elements in the leachate puddles compared to the water samples of "Oued El Maleh" river (OMR).

\section{Mineral salts}

The concentrations of sodium, potassium and magnesium ions in stabilized leachate $\left(\mathrm{Na}^{+}: 5138-5519 \mathrm{mg} / \mathrm{l}\right.$; $\left.\mathrm{K}^{+}: 1147-1202 \mathrm{mg} / \mathrm{l} ; \mathrm{Mg}^{2+}: 226-246 \mathrm{mg} / \mathrm{l}\right)$ are high compared to those of the river waters $\left(\mathrm{Na}^{+}: 533-558\right.$ $\left.\mathrm{mg} / \mathrm{l} ; \mathrm{K}^{+}: 5,604-5,779 \mathrm{mg} / \mathrm{l} ; \mathrm{Mg}^{2+}: 114-118 \mathrm{mg} / \mathrm{l}\right)$, while calcium ion concentrations are almost the same (135$160 \mathrm{mg} / \mathrm{l})$.

Although general limits on discharges into surface or ground waters or maximum permissible values for these metals are not set by the Moroccan standard NM 03.7.001 respectively for these minerals, these elements responsible for the salinity and hardness of the water present very high levels compared to the values usually found in surface and underground waters.

Their impact on water resources for human consumption and industrial uses is limited to the taste and metallic flavor of drinking water and the loss of efficiency in heat exchangers and boilers.

\section{Phosphorus}

The leachate puddles have high contents in this element $(4,767-5,187 \mathrm{mg} / \mathrm{l})$ compared to the river water $(0,546$ 0,556) (around 10 times).

\section{Iron}

The iron contents are high in the leachate puddles $(3,681-4,4 \mathrm{mg} / \mathrm{l})$ compared to the samples taken from the OMR $(0,868-2,183 \mathrm{mg} / \mathrm{l})$ (2 à 4 times).

Iron is one of the metals found naturally in rock and groundwater. Its presence above $0.3 \mathrm{mg} / 1$ (Maximum Allowable for drinking water according to the Moroccan standard) can modify the taste, the odor and the color 
of water; causing mainly aesthetic and gustatory nuisance, as well as problems in water system by promoting the growth of microorganisms and clogging.

\section{Boron, selenium and Strontium}

The boron contents are somewhat similar in the leachate samples L1 and L2 (8,036 and 7,478 mg/l) and remain higher than those obtained in the samples of the Oued E3 and E4 which are approximately equal $(0,349$ et 0,333 $\mathrm{mg} / \mathrm{l})$.

Selenium contents in water samples from the Oued E3 and E4 (7,193 and 9, $92 \mathrm{mg} / \mathrm{l})$ were higher than those of leachate samples $(5,387$ and 4,826 mg / 1). Strontium concentrations are similar in leachate and Oued samples (1.021 to $1.239 \mathrm{mg} / 1)$.

\section{Other metals}

Concentrations of Vanadium, Chromium, Manganese and Nickel (0.385-0.351 mg / 1, 0.914-0.857 mg / 1, 0.245$0.206 \mathrm{mg} / 1$ and $0.23-0.215 \mathrm{mg} / \mathrm{l})$ are also very high in the leachate samples L1 and L2 compared to water of Oued El Maleh (3 to 30 times). Barium contents are also higher in the leachate samples compared to water samples E3 and E4, (E3: $0.157 \mathrm{mg} / 1$ and E4: $0.158 \mathrm{mg} / \mathrm{l})$. Zinc is identical in the leachate samples (0.315 and $0.32 \mathrm{mg} / \mathrm{l})$ and remains much higher than those of water samples E3 and E4 (0.056 $0.049 \mathrm{mg} / 1)$. On the other hand, aluminum concentrations are very high (6 to 12 times) in water samples of Oued E3 and E4 (0.916 and $2.482 \mathrm{mg} / \mathrm{1})$ compared to leachate samples L1 and L2 (0.396 and $0.207 \mathrm{Mg} / 1)$. The Tin concentration is identical in both samples of leachate (about $0.02 \mathrm{mg} / \mathrm{l}$ ) and nil in samples E3 and E4. Copper, Molybdenum, Cadmium, Cobalt, Antimony, Arsenic, Lead, Silver and Selenium are present in trace amounts in all samples of leachate and $\mathrm{OM}$ water.

The contents of $\mathrm{As}, \mathrm{Cd}, \mathrm{Cr}, \mathrm{Cu}, \mathrm{Ni}, \mathrm{Pb}$ and $\mathrm{Zn}$ in the leachate of the same dump before it's closure [3] were very higher than those obtained in this study, L1 and L2 samples. Indeed, it has been shown that some elements can be adsorbed by the soil and subsequently mobilize in the saturated soil layer [8].

Consequently, these concentrations obtained in samples L1 and L2 remain lower than the General Limit Values for Moroccan wastewater discharges [9]. It can be concluded that the metallic pollution generated by the leachate flows decreased after closure of the uncontrolled dumping of Mohammedia city.

Some elements are essential for plant growth and animal feed ( $\mathrm{P}, \mathrm{Si}, \mathrm{Ca}, \mathrm{Fe}, \mathrm{K}$, etc.). However, when the concentration of an element is greater than the absorption capacity of species present in a medium, it may become toxic to the species and to the environment in which it occurs. In addition, several metals toxic to humans $(\mathrm{Cd}, \mathrm{Cr}, \mathrm{Pb}$, etc.) tend to accumulate in the food chain.

\section{Physicochemical characteristics}

Physicochemical characteristics of leachate and the waters of the OMR are presented in figure6.

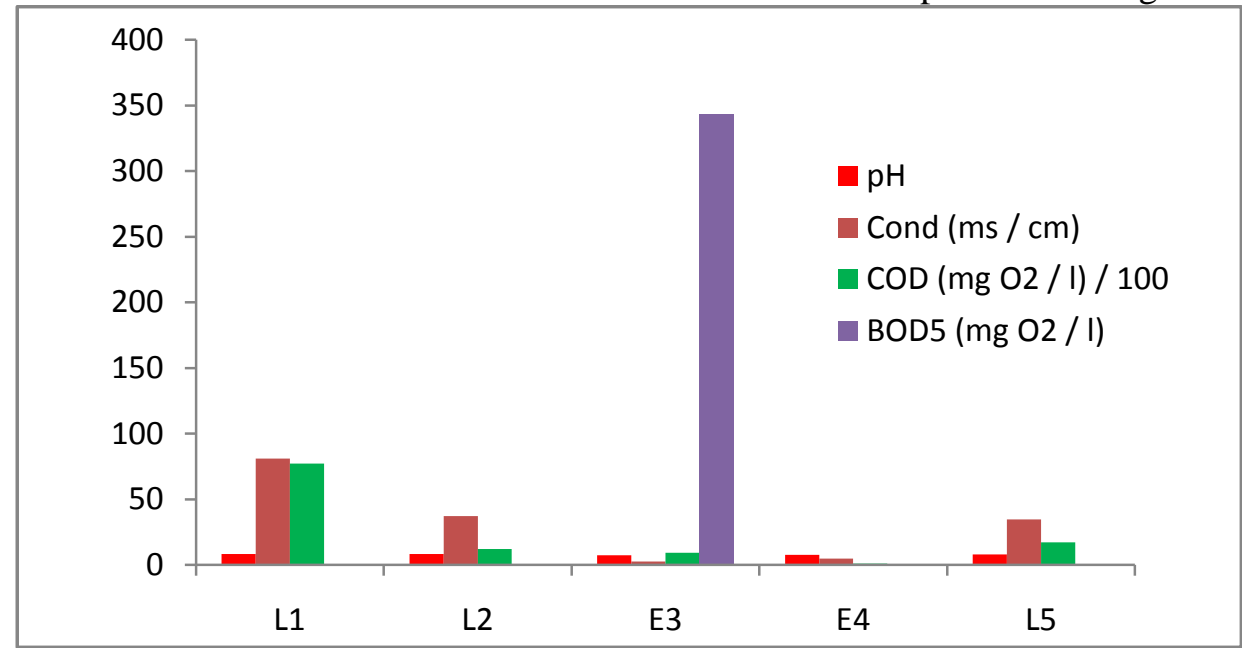

Figure 6: Physicochemical parameters of the leachate and water samples of the OMR

It can be seen that the leachate puddles have a basic character; the $\mathrm{pH}$ varies between 8.02 and 8.32 . The same characteristic was observed by KOUASSI et al. (2004) [3] in a study on the physicochemical characterization of the leachate from a landfill in West Africa: AKOUEDO (Abidjan- Ivory Coast). Furthermore, the pH of the Oued samples was slightly alkaline (7.42 and 7.57). 
The conductivity of the leachate puddles is very high $(37300 \mu \mathrm{S} / \mathrm{cm}-80900 \mu \mathrm{S} / \mathrm{cm})$ compared to that of the Oued waters $(2620 \mu \mathrm{S} / \mathrm{cm}-2461 \mu \mathrm{S} / \mathrm{cm})$. This high conductivity is mainly due to the high concentrations of mineral salt ions (Figure 4). The values of the same order of magnitude are obtained in the landfill of Essaouira city of Morocco $(39983 \mu \mathrm{S} / \mathrm{cm})[10]$ and in the Agadir landfill $(64650 \mu \mathrm{S} / \mathrm{cm})$ [11] and well above the value average obtained in the discharge of the Oujda city (Morocco) (1500 to $4820 \mu \mathrm{S} / \mathrm{cm}$ ) [12].

The Chemical Oxygen Demand (COD) represents organic and inorganic material oxidizable chemically. The COD values obtained for the stabilized leachate samples are very high $\left(1200\right.$ to $\left.7700 \mathrm{mg} . \mathrm{O}_{2} / \mathrm{l}\right)$ compared to those obtained for the other samples $\left(85-923 \mathrm{mg} . \mathrm{O}_{2} / \mathrm{l}\right)$. These concentrations are much higher than the General Limit Values for surface or groundwater discharge in Morocco, set at $500 \mathrm{mg} . \mathrm{O}_{2} / \mathrm{l}$ [9] with the exception of the sample taken at Oued El Maleh $\left(85 \mathrm{mg} . \mathrm{O}_{2} / \mathrm{l}\right)$. The values recorded in a study of the pollutant assessment load of the landfill leachates of Essaouira city Morocco [10] are between 6106 and $13939 \mathrm{mg} . \mathrm{O}_{2} / 1$, although somewhat low values (1048 mg. $\left.\mathrm{O}_{2} / \mathrm{l}\right)$ were obtained in the Tiaret landfill in Algeria [13]. On the other hand, $\mathrm{BOD}_{5}$ is nil for all stabilized leachate and Oued El Maleh samples, while the $\mathrm{BOD}_{5}$ measured for the sample near the discharge point to the Oued is $343 \mathrm{mg}$. $\mathrm{O}_{2} / \mathrm{l}$. This value is in the usual range of Moroccan urban wastewater (200 - $400 \mathrm{mg} . \mathrm{O}_{2} / \mathrm{l}$ ) [9]. The $\mathrm{BOD}_{5}$ measured at the leachate of the new landfill of the same city (Mohammedia) is approximately $29151 \mathrm{mg} . \mathrm{O}_{2} / \mathrm{l}[14]$.

Several studies report that landfill leachate is very rich in organic pollutants $[15,16]$. The absence of organic pollutants at the leachate puddles studied is probably due to the decontamination of this material during the percolation of the liquid in the soil before being overrun at the edge of the OMR, knowing that soil has important purifying properties [17]. With the exception of the sample near wastewater discharge, COD/BOD5 ratios cannot be determined for stabilized leachate samples due to the absence of biodegradable organic matter. This ratio is 2.7 for sample E3 (near wastewater discharge). This value also remains close to the limit of biodegradability. The analysis of all these results shows that the stabilized leachate puddles from leachate percolation from the former landfill are still very rich in inorganic pollutants, composed of several metals. Therefore, water table is still contaminated by non-biodegradable inorganic pollution although the landfill was closed more than six (06) years ago.

\subsection{Soil analysis}

Analysis of soil samples collected near and far from stabilized leachate puddles are illustrated in Figure7(a), Figure7(b) and Figure7(c), for each concentration range. The results presented in these figures show that the concentrations of Boron, Sodium, Magnesium, Potassium, Chromium, Tin and Barium in moist soil samples are much lower than those determined in dry soil samples; taken away from leachate puddles. Metals exist in the soil at various concentrations. Under the action of leachate liquid percolated in the soil, these metallic substances are released from the soil to the liquid, which probably explains the low concentrations in the wet soil samples compared to the dry samples. The concentrations of other elements vary from sample to sample. Indeed, the Aluminum varies between 2.436 and $6.884 \mathrm{ppm}$; Iron between 6.2 and $13.2 \mathrm{ppm}$ and calcium between 24.63 and $113.1 \mathrm{ppm}$. These three elements have very high concentrations compared to the other metallic substances analyzed.

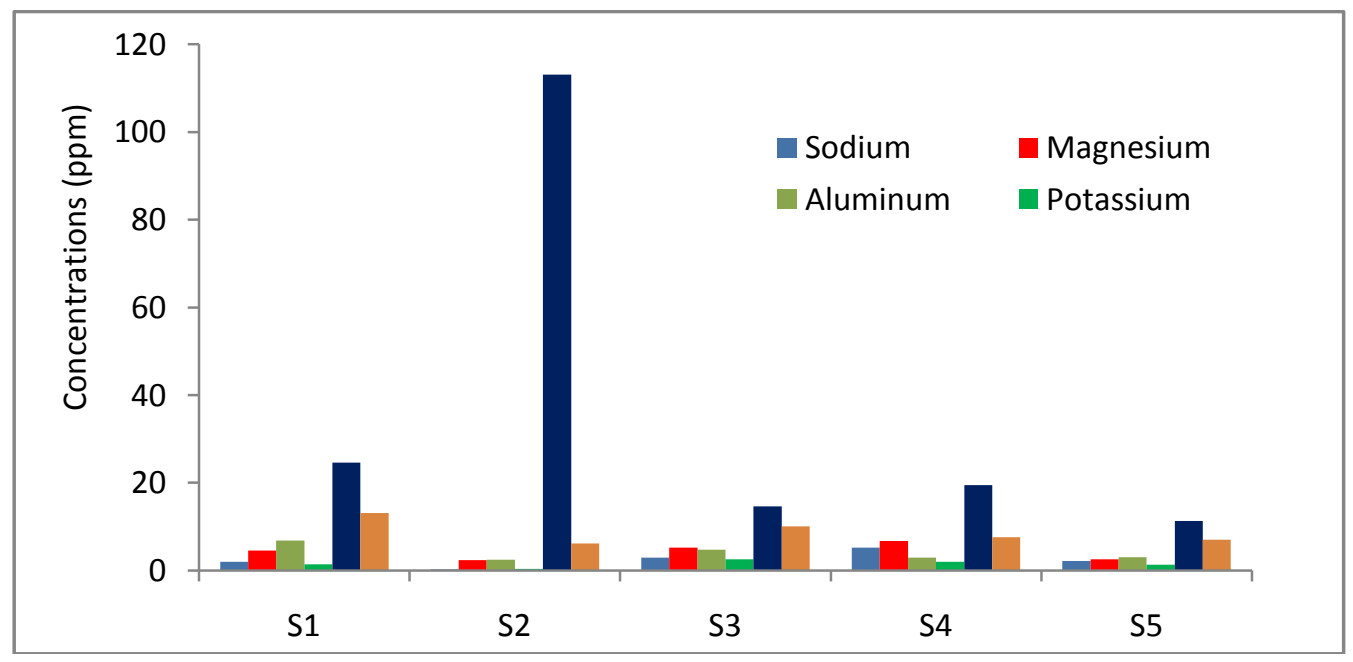

Figure 7(a) : Metals in soil samples (Concentrations range 1) 


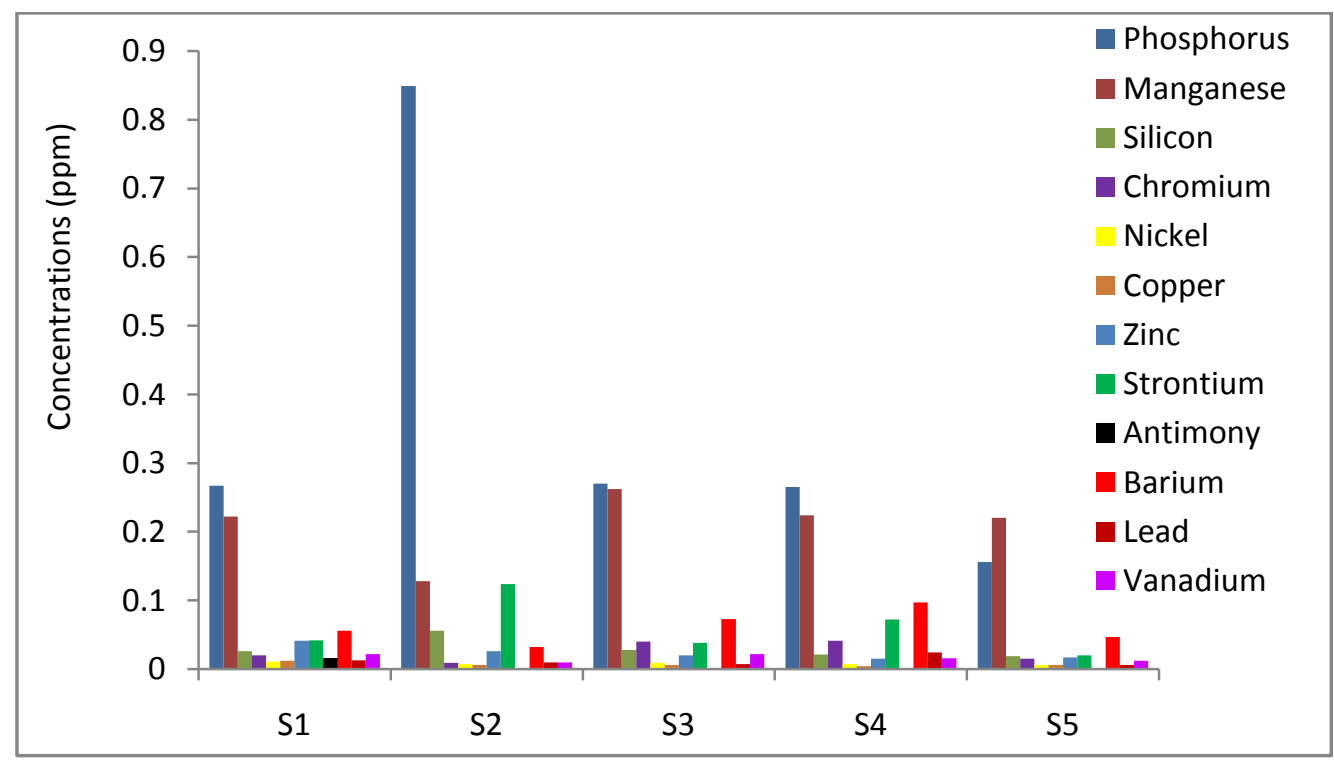

Figure 7(b) : Metals in soil samples (Concentrations range 2)

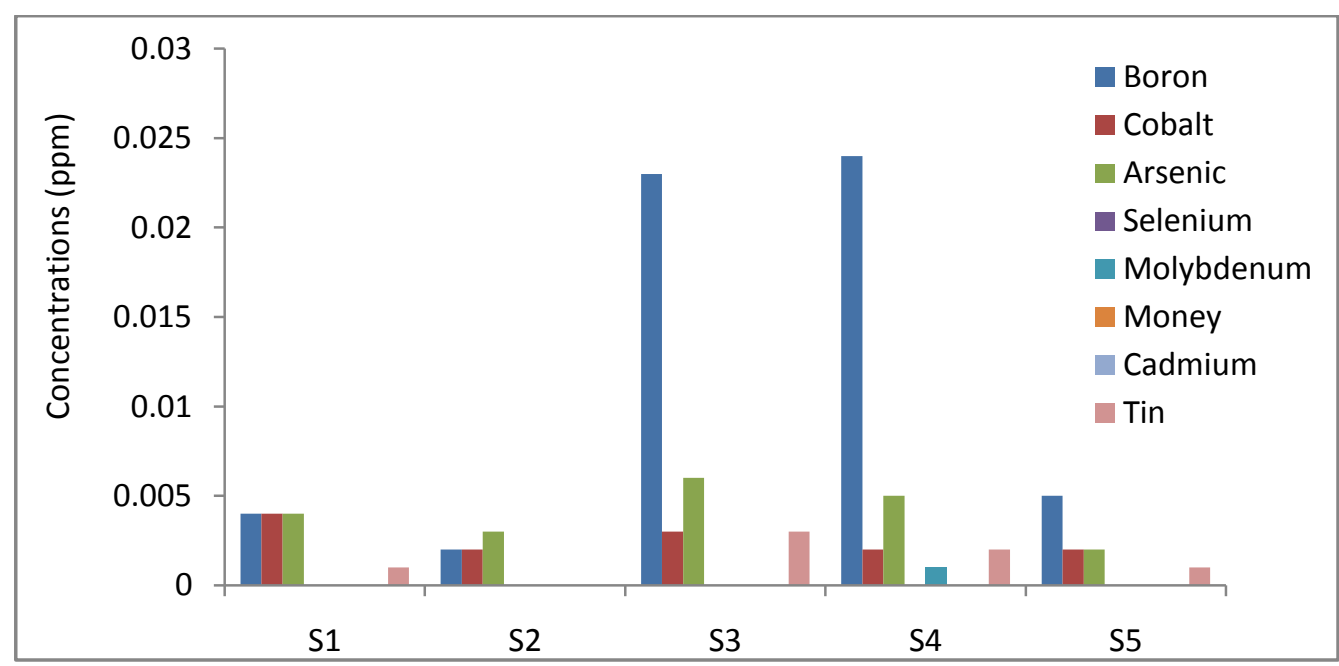

Figure 7(c) : Metals in soil samples (Concentrations range 3)

Moreover, Antimony and Molybdenum are present in these samples as traces in a single sample, while concentrations of Selenium, Silver and Cadmium are absent in all samples. The concentrations of the same elements ( $\mathrm{As}, \mathrm{Cd}, \mathrm{Cu}, \mathrm{Ni}, \mathrm{Pb}$ and $\mathrm{Zn}$ ) obtained in the sediment collected the various points of Fes landfill (Morocco) during the study by Chtioui et al. (2008) [18] are significantly higher than those obtained for the samples studied. This is normal as samples are taken aboard the Oued El Maleh and away from the site of the former dumping site, which is more than 300 meters away, and on the other hand the household waste from Fez city are mixed with industrial waste according to the same authors.

\section{Conclusion}

The results of this study show that the leachate puddles from the former Mesbahiat landfill in Mohammedia city, closed more than six years ago, are heavily laden with metal pollutants. The electrical conductivity of up to $80900 \mu \mathrm{S} / \mathrm{cm}$ reflects the high mineralization of these discharges. The COD is also very high (1200 to 7700 mg. $\mathrm{O}_{2} / \mathrm{l}$ ), and constitutes a high non-biodegradable pollution in these discharges. The $\mathrm{BOD}_{5}$ absent in these leachate puddles is due to the elimination of organic pollution from the soil during leachate percolation initially generated by the landfill.

Otherwise, the concentrations of the elements $\mathrm{As}, \mathrm{Cd}, \mathrm{Cr}, \mathrm{Cu}, \mathrm{Ni}, \mathrm{Pb}$ and $\mathrm{Zn}$, obtained in samples of leachate puddles remain below the General Limit Values for Moroccan wastewater discharges. It can be concluded that 
metal pollution due to the analyzed metals and generated by the leachate flows decreased after closure of the landfill.

The soil at the side of Oued El Maleh River seems less contaminated by these leachate residues since the high concentrations of metal pollutants are not outstanding.

\section{References}

1. Hakkou R., Wahbi M., Bachnou A., Elamari K., Hanich., Hibti M, B ENG GEOL ENVIRON. 60 (2001) 325-336

2. Idlahcen A., Souabi S., Bouezmarni M., Taleb A., Digua K, Scientific Study \& Research, Chemistry \& Chemical Engineering, Biotechnology, Food. 15(1) (2014) 035 - 050

3. Kouassi A.E., Ahoussi K.E., Koffi Y.B., Kouame I.K., Soro N., Biemi J, Larhyss Journal, $N^{\circ} 19$ (2014) $1112-3680$

4. Tahiri A.A., Laziri F., Yachaoui Y., El Jaafari S., Tahiri A.H., European Scientific Journal. 35 (10) (2014) $1857-7881$

5. Chaouki Z., El Mrabet I., Khalil F., Ijjaali M., Rafqah S., Anouar S., Nawdali M., Valdés H., Zaitan. H, J. Mater. Environ. Sci. 8 (8) (2017) 2781-2791

6. Elkadi A., Maatouk M,, Tarik C., Raissouni M, J. Mater. Environ. Sci. 6 (11) (2015) 3207-3216

7. Gloaquin A. Techniques Sciences Méthodes. 4 (1997) 58-67

8. Kouame K., Gone D.L., Savane I., Kouassi E.A., Koffi K., Goula B.T.A., Diallo M, Revue Internationale des Sciences et Technologie. 2(1) (2006) 39-56

9. MEMEE. Arrêté $n^{\circ} 13.2942$ du 07 Octobre 2013 portant fixation des Valeurs Limites Générales de rejet. (2014)13

10. Chiguer H., El Khayyat F., El Rhaouat O., Rifki R., Bensaid A., El Kharrim K., Belghyti D., International Journal of Innovation and Applied Studies. 14 (2016) 863-874

11. Commune Urbaine d'Agadir et LIME de la Faculté des Sciences Ain Chock - Casablanca, Maroc., Bulletin d'analyse de lixiviat à la décharge contrôlée du grand Agadir-Maroc. 16-10 (2010) 5

12. El Kharmouz M., Sbaa M., Chafi A., Saadi S., Larhyss Journal. 16 (2013) 105-119

13. Mekaikia M.M., Belabbed B.E., Djabri L., Hani A., Laour R, Courrier du Savoir. Nº8 (2007) 93-99

14. Commune Urbaine de Mohammedia et LPEE, Maroc., Bulletin d'analyse de lixiviat de la décharge contrôlée interprovinciale de Mohammedia et Benslimane-Maroc. (2013) 6

15. Khalil F., Bouaouine O., Chtioui H., Souabi S., Aboulhassan M.A., Ouammou A., J. Mater. Environ. Sci. 6 (5) (2015) 2028-2508

16. Souabi S., Touzar K., Chtioui H., Khalil F., Digua Kh., Tahiri M, Déchets, Sciences et Techniques. 58 (2010)

17. Kale, S.S., Kadam, A.K., Kumar, S., Pawar, N.J., Environ Monit Assess. 162 (2010) 327-346

18. Chtioui H., Khalil F., Souabi S., Aboulhassan MA, Déchets, Sciences et Techniques. 49 (2008)

(2017) ; http://www.jmaterenvironsci.com 